\title{
Nerve Conduction Study in Bell's Palsy
}

\author{
Shah SK${ }^{1}$, Kothari RP², Bassi SD ${ }^{3}$
}

\section{ABSTRACT}

Background: Nerve conduction study (NCS) is an important electrophysiological tool that can be used for the measurement of the latency and amplitude of the facial nerve. The NCS helps in predicting the prognosis of patients with Bell's palsy. Evaluation of NCS of patients with Bell's palsy may have contribution in counselling and management of the patient. Objective: The study was aimed to study the state of nerve damage in patients with Bell's palsy. Methods: The latency and amplitude of facial nerve stimulating bilateral Orbicularis Oculi and Orbicularis Oris muscles were assessed and noted in 24 patients of Bell's palsy. Results: 15(62.5\%) of the patients had significant axonal injury affecting one side and only $1(4.16 \%)$ patient had demyelinating injury. The total of $8(33.33 \%)$ patients had insignificant axonal injury of the facial nerve in comparision with the normal side. Conclusions : Nerve conduction study shows predominant axonal type of facial nerve injury in patients with Bell's palsy and hence provides valuable information regarding the prognosis and the state of nerve damage in patients with Bell's palsy.

Key words: Nerve Conduction Study, Bell's Palsy

\section{INTRODUCTION}

Electronic equipment has become the important tool as investigation in current era. Nerve Conduction Study of the peripheral nerve also have served this purpose. It has been used since decades as a part of investigation of Facial Palsy. The state of neural damage or function can be assessed in facial palsy using Nerve conduction study. Bell's Palsy, named after Sir Charles Bell, is an idiopathic lower motor neuron inflammation of the facial nerve. The incidence of Bell's Palsy is 25 in 100000 people $^{1}$. It is more common in third decades ${ }^{2}$. The study aims to know the motor nerve conduction test of facial nerve in Bell's palsy and compare it with that of previous studies; in context at mid-western region of Nepal.

\section{SUBJECTS AND METHODS}

This is the retrospective study done from August 2016 to May 2017 at Neurophysiology Lab of Nepalgunj Medical College and Teaching Hospital, Kohalpur. The total of 24 patients diagnosed with Bell's palsy underwent motor nerve conduction study of facial nerve. The patients with facial paralysis caused by stroke, trauma or other causes were not included in the study. The patients with duration of Bell's palsy of one month or less underwent motor nerve conduction study of bilateral facial nerve. RMS EMG/NCV/EP machine was used for this purpose. Bilateral Orbicularis Oculi and Orbicularis Oris muscles were tested from ipsilateral anterior tragus and recorded using

\footnotetext{
1. Dr. Sanjib Kumar Shah

2. Prof. R. P. Kothari

3. Prof. S. D. Bassi
}

Address for correspondence:

Dr. Sanjib Kumar Shah

Department of Medicine

Nepalgunj Medical College Teaching Hospital

Kohalpur, Nepal

Email: sanjibkshah@gmail.com supramaximal stimulation. The latency and the compound motor action potential were noted. The latency below $4.1 \mathrm{~ms}$ and the amplitude difference between two sides less than $50 \%$ were considered normal ${ }^{4}$.

\section{RESULTS}

The age range was 4 to 74 years of patients with $15(62.5 \%)$ female and $9(37.5 \%)$ male. The mean age of the patient was $37.13 \pm 17.51$. The maximum number of cases were seen in 31 40 years of age. Our study showed axonal loss in 15(62.5\%) and only one (4.16\%) patient had demyelinating injury among the patients. The rest of the patients had decreased amplitude in the affected side compared to the normal side suggesting mild or insignificant axonal loss. Among the 24 patients, only four had complete facial paralysis, i.e. decreased amplitude on upper and lower part of the face.

\begin{tabular}{|c|c|c|c|c|c|}
\hline & & Frequency & Percent & $\begin{array}{c}\text { Valid } \\
\text { Percent }\end{array}$ & $\begin{array}{c}\text { Cumulative } \\
\text { Percent }\end{array}$ \\
\hline \multirow{7}{*}{ Valid } & $1-10$ & 2 & 8.3 & 8.3 & 8.3 \\
\hline & $11-20$ & 2 & 8.3 & 8.3 & 16.7 \\
\hline & $21-30$ & 2 & 8.3 & 8.3 & 25.0 \\
\hline & $31-40$ & 13 & 54.2 & 54.2 & 79.2 \\
\hline & $51-60$ & 2 & 8.3 & 8.3 & 87.5 \\
\hline & $>60$ & 3 & 12.5 & 12.5 & 100.0 \\
\hline & Total & 24 & 100.0 & 100.0 & \\
\hline
\end{tabular}

Table I: Distribution of Patients according to age group

\section{DISCUSSION}

Electrodiagnostic study is an important test that contribute the understanding of state of the neural function. In our study, the peak incidence was on 30-40 years of age group which is in agreement with the study done by C. Prescott, Pietersen (1982) and Adour et al. (1978). ${ }^{2,3,7}$ The preponderance of female over 
male was also similar to that by C. Prescott. However, in our small sized study left sided weakness predominated which was not in line of agreement with that of C.Prescott, Pieterson and Adour et $\mathrm{al}^{2,3,7}$. The predominant axonal type of injury seen in Bells palsy among our patients corresponds with the study of Yasukawa et al, Wang et al $^{5,6}$.

\section{CONCLUSION}

Bell's palsy affects patients with axonal loss on the affected side with incomplete facial weakness being the common type of involvement. Nerve conduction study of facial nerve is an important tool to assess the functional state of nerve. Assessing the facial nerve excitability also helps in predicting the prognosis in Bell's Palsy.

\section{REFERENCES}

1. Katusic SK, Beard CM, Wiederholt WC, Bergstralh EJ, Kurland LT. Incidence, clinical features and prognosis in Bell's palsy, Rochester, Minnesota, 1968-1982. Ann Neurol 1986;20:622-627.

2. Pietersen, E. (1982) Natural History of Bell's Palsy. In Disorders of the Facial Nerve, Graham, M. D. and House, W. F. Eds., Raven Press, New York, pp. 307-312.

3. Adour, K. K. and Diamond, C. (1982) Decompression of the facial nerve in Bell's Palsy: A historical review. Otolaryngology-Head and Neck Surgery, 90: 453-460.

4. David C. Preston, Barbara E. Shapiro. Electromyography and Neuromuscular Disorders : Clinical-Electrophysiologic Correlations. Third Edition.

5. Yasukawa M, Yasukawa K, Ohnuma H. Prognostic diagnosis of facial palsy with electroneurography. Masui-Japanese Journal of Anesthesiology. 1995;44: 378-87.

6. Wang Y, Zhang S, Xu H. A report of 164 cases of Bell's palsy. Chinese Journal of Otorhinolaryngology. 1996; 31: 334-37.

7. C. A. J Prescott. Idiopathic facial nerve palsy. (The effect of treatment with steroids). The Journal of Laryngology and Otology. 1988;102: 403-407. 